\title{
SE BUSCA SENTIDO COMÚN
}

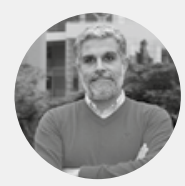

\author{
JEAN P. GARCÍA \\ - Profesor de Evaluación de Proyectos de Inversión Privada \\ Carrera de Administración y Finanzas \\ Facultad de Negocios, UPC
}

Hace unos días revisaba algunos de los documentos de investigación que ha publicado el profesor Pablo Fernández, Ph.D. en Business Economics y titular de la cátedra PricewaterhouseCoopers de Finanzas Corporativas en la Escuela de Negocios IESE de la Universidad de Navarra. El profesor Fernández es conocido, tanto por sus trabajos de investigación, como por sus asesorías empresariales, todo ello relacionado con la valoración de negocios. Al ser uno de los principales especialistas hispanos en valuación, siempre resulta interesante releer sus reflexiones sobre este tema, que ocupa una posición importante dentro del ámbito de estudio de las finanzas corporativas.

En sus propias palabras, la valoración de un negocio "es un ejercicio de sentido común que requiere unos pocos conocimientos técnicos y mejora con la experiencia. [...] Casi todos los errores en valoración se deben [...] a falta de conocimientos o a falta de sentido común". Probablemente, para todo profesional de finanzas esta cita no pasa de ser una obviedad: el que el sentido común sea un ingrediente indispensable en el ejercicio de la profesión, es axiomático, tautológico. Es por ello que sorprende la facilidad con la que los mismos especialistas, que momentos antes sonreíamos condescendientemente ante la frase del profesor Fernández, caemos luego en errores tan elementales y de bulto como el que motiva la presente columna.

Es aceptado que, aunque existe una gran variedad de métodos para estimar el valor de un negocio, ninguno produce resultados tan sólidamente respaldados por la teoría financiera como el método de descuento de flujos futuros, el cual, como su nombre indica, requiere de la estimación de los flujos de caja que el negocio será capaz de generar en los años venideros, flujos que, luego de haber atendido las necesidades operativas y de inversión, sirvan para satisfacer los requerimientos de los agentes que aportaron el financiamiento. El descuento de estos flujos se realiza utilizando una tasa de descuento apropiada, que refleja el costo de cada una de las fuentes de fondos, así como su importancia relativa dentro de la estructura total de financiamiento. Esta tasa de descuento es conocida, por su nombre en inglés, como weighted average cost of capital (WACC)
La estimación de los flujos futuros de caja requiere de un análisis exhaustivo del negocio, tanto interno, como externo. Luego de ello es fundamental hacer suposiciones educadas sobre las tendencias futuras y los resultados posibles, esperados y esperables. Por otro lado, el WACC también presenta una serie de desafíos para su correcta estimación, como, por ejemplo, la determinación del costo de oportunidad de los socios del negocio o bien la relación entre los valores de mercado de la deuda y del aporte propio. Todo ello, en suma, hace imprescindible la conjunción de conocimientos y sentido común, potenciados por la experiencia del valorador y también, por qué no decirlo, por un poco de suerte. Es por ello que no sorprende, al revisar los documentos que, sobre valoración de empresas peruanas, se pueden encontrar en la Bolsa de Valores de Lima (BVL), hallar informes con cientos de páginas. En particular, me referiré a uno de reciente elaboración sobre la valoración de una conocida e importante empresa peruana del sector minero, documento que cuenta con alrededor de 240 páginas. Si obviamos los diversos anexos, el informe se reduce a la nada despreciable suma de 150 páginas, de las cuales, grosso modo, 60 (40\%) están dedicadas al análisis interno y externo de la empresa y de sus subsidiarias; 51 (34\%) a la descripción de los supuestos de valoración y a las proyecciones de los flujos; y 30 (20\%), en partes iguales, tanto al marco teórico, como al análisis de resultados, las conclusiones y las recomendaciones. En las nueve páginas restantes (6\%), se desarrollan la introducción y generalidades del documento, así como la justificación y el cálculo del WACC.

Debería llamar poderosamente la atención el hecho de que el análisis de uno de los componentes claves del método de valorización utilizado sea despachado tan ejecutivamente, en alrededor de cinco páginas. ¿Cómo puede ser esto posible? Pues, debido a que los "practicantes" de la valoración de empresas hemos desarrollado, como parte de nuestro instrumental quirúrgico, una serie de herramientas que, haciendo uso de algunos supuestos convenientemente simplificadores, convierten el cálculo del WACC en un mero trámite que no justificaría una atención más prolongada. Sin embargo, lo anecdótico es que el cálculo de la tasa de 
descuento dista de ser un detalle menor: siguiendo con el caso de la conocida empresa minera peruana, aludida en el párrafo anterior, una variación de un punto porcentual en la tasa estimada en el documento, haría que el resultado de la valorización cambiase en aproximadamente $4 \%$, es decir, en la nada despreciable suma de 34 millones de dólares.

Lo que ocurre es que hemos archivado, en un rincón remoto de nuestras mentes, los supuestos que asumimos cuando utilizamos nuestras herramientas, supuestos tales como endeudamientos perpetuos y préstamos sin riesgo, que arrancan sonrisas de incredulidad a los estudiantes cuando se discuten estos temas en el salón de clase. Y, a pesar de ello, seguimos usando nuestras herramientas una y otra vez como autómatas, sin cuestionarnos, sin pensar. Aparentemente, existe una relación inversa entre el uso de herramientas sofisticadas y el del sentido común. Vivimos rodeados de tecnología, de herramientas diseñadas para simplificar tareas, pero estas herramientas no pueden ni deben reemplazar el sano ejercicio de nuestro propio juicio, de eso que llamamos "sentido común". 